\title{
Improving the net present value by estrus synchronization in non-pregnant dairy cows detected by ultrasound 25 days after artificial insemination
}

\author{
SILVIU-IONUȚ BORŞ ${ }^{1 *}$, ȘTEOFIL CREANGĂ ${ }^{1,2}$, ALINA BORŞ ${ }^{3}$ \\ ${ }^{1}$ Research and Development Station for Cattle Breeding, 707252 Dancu, Iaşi, Romania \\ ${ }^{2}$ Faculty of Animal Sciences, University of Agricultural Sciences and Veterinary Medicine of Iaşi, \\ 700490, Iaşi, Romania \\ ${ }^{3}$ Department of Public Health, Faculty of Veterinary Medicine, University of Agricultural Sciences \\ and Veterinary Medicine, 700489, Iaşi, Romania
}

\begin{abstract}
Pregnancy rates in Holstein cow showed a substantial decline in the past years, which caused intensive estrus synchronization programs for non-pregnant cows to shorten the period between an unsuccessful artificial insemination (AI) and the next attempt on the same cow. The program implied estrus synchronization of non-pregnant cows with either prostaglandin or GnRH followed by prostaglandin after 7 days, then GnRH 2 days later and AI during the following day. Cows included in the estrus synchronization program recorded an improvement of the pregnancy rate at 130 days in milk compared to those in which this strategy was not applied $(56.7 \%$ vs. $37.5 \%$; $\mathrm{P}<0.05)$. The economic analysis revealed a difference in the net present value (NPV; \$/cow/year) of $\$ 10.1 /$ cow/year between the two programs (rebreeding the non-pregnant cows following estrus synchronization program and AI at detected estrus vs. AI at detected estrus). In summary, rebreeding the non-pregnant dairy cows after early negative pregnancy diagnosis ( 25 days after AI) using estrus synchronization program can improve the pregnancy rate and economic value of dairy farms.
\end{abstract}

Keywords Dairy cows, early pregnancy diagnosis, estrus synchronization, profitability.

To cite this article: BORŞ SI, CREANGĂ Ş, BORŞ A. Improving the net present value by estrus synchronization in non-pregnant dairy cows detected by ultrasound 25 days after artificial insemination. Rom Biotechnol Lett. 2021; 26(4): 2818-2824. DOI: $10.25083 / \mathrm{rbl} / 26.4 / 2818-2824$ 


\section{Introduction}

A precise early pregnancy diagnosis is an important tool for better reproductive management in dairy cattle. Early pregnancy diagnosis contributes to a profitable breeding program by enabling the farmer to identify open animals and to rebreed them at the earliest opportunity. The number of days that a cow remains non-pregnant after the voluntary waiting period has already been correlated with reduced profitability (DE VRIES, 2006). Thus, the early identification of cows that fail to conceive can be used to obtain greater economic gain from reproductive programs in dairy herds (FRICKE, 2002; INCHAISRI et al, 2010).

In dairy cattle, different methods can be employed to establish pregnancy status. Such methods are the return to estrus (SENGER, 1994), the rectal palpation of the reproductive tract (COWIE, 1948; WISNICKY and CASSIDA, 1948), the ultrasound examination of the reproductive tract (FRICKE, 2002), the milk progesterone tests (HOLTZ and NIGGEMEYER, 2019) and the tests for pregnancy-associated glycoproteins (PAGs) in blood or milk (SHAHIN et al, 2014; COMMUN et al, 2016). In practice, most of the farmers currently use transrectal ultrasonography for early pregnancy diagnosis in cattle. The other methods are not largely utilized in farm conditions due to the limitations they inherit. Ideally, an early pregnancy test would have high sensitivity and high specificity, should be inexpensive to conduct, would consist of a simple cow-side test (usable in field condition) and should determine pregnancy status in a timely manner (FRICKE et al, 2016).

The transrectal ultrasonography is a minimally invasive, accurate, and efficient technique for early pregnancy diagnosis which can be established starting with day 25 after artificial insemination (AI), depending on the experience of the veterinarian. Furthermore, transrectal ultrasonography can provide additional information on ovarian structures, can identify twins and determine the fetal viability (FRICKE, 2002).

Over time, the pregnancy rates in Holstein cows showed a substantial decline with a current value near 35\% (LUCY, 2001; WALSH et al, 2011; NORMAN et al, 2016). In these conditions, resynchronization programs to prepare non-pregnant cows for subsequent AI need to be developed and further assessed in order to manage reproduction in lactating dairy cows within commercial dairies (FRICKE, 2002). Some studies have evaluated pregnancy rate and time to pregnancy using different reproductive programs (PURSLEY et al, 1997a; CERRI et al, 2004; TENHAGEN et al, 2004), but very few have evaluated the economic benefits of using such programs (TENHAGEN et al, 2004; Giordano et al, 2011). To our knowledge, there is no report of the net present value of rebreeding non-pregnant Holstein Friesian cows after early negative pregnancy diagnosis, 25 days after AI. The aim of the present study was to assess the accuracy of ultrasonography in early pregnancy diagnosis (day 25 after AI) and to estimate the efficacy of an estrus synchronization program for non-pregnant cows as it concerns the improvement in pregnancy rate until 130 days in milk and the net present value ( $\$ /$ cow/year).

\section{Materials and Methods}

\section{Animals and study design}

The study was conducted at the Research and Development Station for Cattle Breeding Dancu-Iasi (SCDCB Dancu-Iasi), Romania, on 70 Holstein Friesian cows artificially inseminated by a single technician in the interval 45-90 days in milk, which were divided in two groups, control (C group, $n=40$ ) and experimental (E group, $\mathrm{n}=30$ ). During the study period, the farm milked approximately 330 cows, two times/day, with a daily average of $26 \mathrm{~kg}$ of milk/cow/day. The cows were housed in free stall barns with concrete covered with mattresses and were fed a Total Mixed Ration (TMR) two times/day with ad libitum access to water. Standard management practices were followed to maintain the animals healthy. Each cow had a voluntary waiting period of 45 days in milk. Estrus detection was carried out two times/day, early in the morning and late in the evening, using visual examination of the animal for at least 30 minutes. The estrus signs were the attempt to mount the other cows, chasing herd mates, restlessness, chin-resting, sniffing of the vagina of herd mates and bellowing, congestion, relaxation and mucus discharge from the vulva. Manifestation of standing estrus was considered to be the sign of true estrus.

The control group ( $\mathrm{C}$ group) consisted of 40 clinically healthy cows (16 primiparous and 24 multiparous). The cows which were diagnosed as non-pregnant after transrectal ultrasound examination (day 25 after AI) were not subjected to the estrus synchronization program and were $\mathrm{AI}$ at the next spontaneous estrus manifestation.

The experimental group (E group) consisted of 30 clinically healthy cows (12 primiparous and 18 multiparous). The cows which were diagnosed as non-pregnant after transrectal ultrasound examination (day 25 after $\mathrm{AI}$ ) 
were subjected to the estrus synchronization program in order to return to estrus and be reinseminated at the earliest opportunity. When a corpus luteum (CL) was identified during transrectal ultrasonography, a single dose of $500 \mu \mathrm{g}$ Cloprostenol (Estrumate, MSD Animal Health, Holland) was administered by intramuscular injection. When follicular structures such as ovarian follicles (size, 3-20 mm) at different stages of development rate and/or follicular cysts (size, >20 mm) were identified, a GnRHanalogue was administered intramuscularly (Receptal, MSD Animal Health, Holland) in doses of 10 and $20 \mu \mathrm{g}$, respectively. After 7 days, a single dose of Cloprostenol was administered followed by GnRH-analogue in day 9 and $\mathrm{AI}$ in day 10 (approximately 12-24 h later).

One experienced veterinarian conducted all ultrasound examinations and hormone injections. The transrectal ultrasonography (WED $3000 \mathrm{~V}$, Shenzhen Well.D Medical Electronics Co., Ltd., China) was performed 25 days after AI and repeated in day 45 for pregnancy confirmation (the reference test). Ultrasound scanning of the uterus and the ovaries was processed by using a 5.5-7 MHz rectal linear probe for diagnosis and confirmation of pregnancy. The visualization of a fluid-filled uterine horn (amniotic vesicle) was used as positive indicator of the pregnancy.

\section{Economic analysis}

To assess the economic impact of rebreeding the non-pregnant cows after a therapy targeting the ovarian structures, a 330-cow commercial dairy herd was simulated using the UW-DairyRepro\$ decision support tool (GIORDANO et al, 2011) with the modifications described by Giordano et al, (2013). The reproductive program simulated for the first AI service was similar to that used for the experiment (heat breeding), whereas the second reproductive management programs compared in the present study used the estrus synchronization initiated 25 days after $\mathrm{AI}$ in $\mathrm{E}$ group in combination with $\mathrm{AI}$ at detected estrus vs. AI at detected estrus in $\mathrm{C}$ group. The pregnancy rates were set at $37.5 \%$ in $\mathrm{C}$ group and $56.7 \%$ in E group, based on the results of the first part of the study. Total pregnancy loss was set at $13.3 \%$ for C group and $11.8 \%$ for E group. The reproductive program cost used for $\mathrm{E}$ group included $\mathrm{GnRH}$ at $\$ 2.6 /$ dose, labor for hormone injections at $\$ 15 / \mathrm{h}$, and $\mathrm{AI}$ (including semen unit and labor) at $\$ 15 / \mathrm{AI}$. The pregnancy diagnosis cost was set at $\$ 100 / \mathrm{h}$. In addition, the simulated scenarios included productive and economic parameters. For productivity, the numbers were $8000 \mathrm{~kg}$ of milk of rolling herd in average, $36.4 \%$ culling rate, $3 \%$ mortality rate and $4.9 \%$ stillbirth rate. As for the economic parameters, the price of milk = $\$ 16 / \mathrm{cwt}$, the feed cost for lactating cows $=\$ 0.07 / \mathrm{lb} \mathrm{DM}$, the feed cost for dry cows $=\$ 0.06 / \mathrm{lb} \mathrm{DM}$, the female calf value $=\$ 182 /$ calf, the male calf value $=\$ 107 /$ calf, the replacement heifer $=\$ 530 /$ heifer, the salvage value of culled cow $=\$ 683 / \mathrm{cow})$. The model estimated net present value (NPV; \$/cow/year) differences for the reproductive program consisting in rebreeding the non-pregnant cows following estrus synchronization program and $\mathrm{AI}$ at detected estrus vs. AI at detected estrus.

\section{Statistical analysis}

The accuracy of ultrasound examinations used for early pregnancy diagnosis was evaluated by establishing the sensitivity and the specificity according to Broaddus and DeVries, (2005):

- Sensitivity $=$ No. of animals correctly diagnosed as pregnant/No. of animals correctly diagnosed as pregnant + pregnant declared wrongly as non-pregnant;

- Specificity $=$ No. of animals correctly diagnosed as non-pregnant /No. of animals correctly diagnosed as non-pregnant + non-pregnant declared wrongly as pregnant.

Data were analyzed by least squares analysis of variance using GLM procedures of SAS (SAS Institute, Cary, NC, USA). The fixed effects in the model included group, parity (primiparous vs. multiparous) and their interaction. A chi-square test $\left(x^{2}=\sum \frac{(O-E)^{2}}{E}\right.$ or $x^{2}=$ Sum of (Observed - Expected $)^{2} /$ Expected) was used in the final analysis after removal of non-significant interactions. The differences between the two groups were considered to be statistically significant when $\mathrm{P}<0.05$.

\section{Results}

Pregnancy diagnosis by transrectal ultrasonography performed 25 days after AI showed sensitivity and specificity of $93.3 \%$ and $96.3 \%$ for C group and of $91.7 \%$ and $95 \%$, for E group, respectively (Table 1).

As the pregnancy rate after first insemination was approximately similar in both groups (35\% vs. $36.7 \%)$, approximately $64 \%$ or more of the cows failed to conceive. In this study the corpus luteum was diagnosed in a large number of non-pregnant cows $(61.5 \%$ of cases for $\mathrm{C}$ group and $73.7 \%$ for $\mathrm{E}$ group). In small proportions, follicular cysts and ovarian follicles were also detected, at a rate of $11.5 \%$ and $27 \%$ respectively in $\mathrm{C}$ group, vs. $5.3 \%$ and $21 \%$, respectively in $\mathrm{E}$ group. After treatment of the non-pregnant cows from $\mathrm{E}$ group, a superior pregnancy rate $(56.7 \%)$ until 130 days in milk was obtained compared with $\mathrm{C}$ group (37.5\%), $(\mathrm{P}<0.05$, Table 1). 
Table 1. Results of the early pregnancy diagnosis and the improvement of pregnancy rates in the breeding interval 45-130 days in milk by rebreeding the non-pregnant cows after estrus synchronization

\begin{tabular}{lcc}
\hline Variables & C group & E group \\
\hline No. of cows scanned & 40 & 30 \\
No. of cows non-pregnant at first pregnancy diagnosis (25 days after AI) & 26 & 19 \\
No. of cows pregnant at first pregnancy diagnosis (25 days after AI) & 14 & 11 \\
Pregnant cows diagnosed as non-pregnant (false negative) & 1 & 1 \\
Non-pregnant cows diagnosed as pregnant (false positive) & 1 & 1 \\
No. of cows pregnant at 45 days after AI & 14 & 11 \\
Sensitivity of ultrasonography at 25 days after AI & $93.3 \%$ & $91.7 \%$ \\
Specificity of ultrasonography at 25 days after AI & $96.3 \%$ & $95 \%$ \\
Pregnancy rate at first pregnancy diagnosis & $35 \%$ & $36.7 \%$ \\
Non-pregnant cows, diagnosed with ovarian follicles at different & $27 \%$ & $21 \%$ \\
development stages (size, 3-20 mm) & $61.5 \%$ & $73.7 \%$ \\
Non-pregnant cows, diagnosed with corpus luteum & $11.5 \%$ & $5.3 \%$ \\
Non-pregnant cows, diagnosed with follicular cyst(s) & & 0 \\
(size, $>20$ mm) & 15 & 18 \\
Non-pregnant cows, treated for estrus induction & $37.5 \%$ b & $56.7 \% \mathbf{a}$ \\
No. of cows pregnant at 130 days in milk & 5 \\
Pregnancy rate at 130 days in milk & & \\
\hline
\end{tabular}

a, b Different superscripts indicate significant differences between groups (a vs. b, a > b, $\mathrm{P}<0.05$ ), (chi-square analysis)

The simulating program used in this experiment which included the improvement of the pregnancy rate at 130 days in milk by rebreeding the non-pregnant cows as a result of estrus synchronization showed a NPV of $\$ 10.1 /$ cow/year greater for $\mathrm{E}$ group $(\$ 2,197 /$ cow/year) compared with C group (\$2,187/cow/year).

\section{Discussion}

This study presents an estrus synchronization program for non-pregnant cows, with simple targeted hormonal intervention according to ovarian structures identified at transrectal ultrasonography, which shortens the period between an unsuccessful artificial insemination and the following attempt.

The pregnancy diagnosis by transrectal ultrasonography performed 25 days after AI, presented values comparable with the results obtained by others (PIETERSE et al, 1990; FILTEAU and DESCOTEAUX, 1998). This indicates that on day 25 after AI, transrectal ultrasonography can efficiently diagnose the non-pregnant cows that are eligible for estrus synchronization programs. On the other hand, some studies (REAL et al, 2006; ROMANO et al, 2006) observed low sensitivity on day 25 after AI possibly because of the difficulties in visualizing the gestational vesicle or because of the ambiguities in interpreting the ultrasonography image (BRAGANÇA et al, 2018). Some errors can occur, and they are costly: a false positive diagnosis can result in not inseminating the open cows in due time, whereas a false negative diagnosis might lead to abortion when prostaglandin is administered. To avoid the abortion when prostaglandin is administered, we recommend against treating the cows if the uterus shows presence of fluid at day 25 after AI. In our experiment, the false negative pregnancy diagnosis was present in the case of two cows, with very small dimensions of the amniotic vesicle in the uterus. The cows were recorded as non-pregnant but were not treated, because the pregnancy diagnosis could not be certain. In day 45 after AI, the pregnancy was confirmed. Since the cost of abortion is higher, rebreeding the cows in such ambiguous cases is not justified. We consider that the specificity of the transrectal ultrasonography used for pregnancy diagnosis must be around $90-100 \%$ when this reproductive management is applied. Other authors recommended administering prostaglandin to cows found open starting with day 35 after AI for rectal palpation and 28 days for ultrasound exam (ROSENBAUM and WARNICK, 2004).

Early pregnancy diagnosis is crucial for shortening the calving interval by enabling the veterinarian to identify open cows in order to rebreed them. In our study, the pregnancy rate at first AI did not differ between groups and the results are similar to those of previous studies (PURSLEY et al, 1997a, 1997b; FRICKE et al, 1998; JOBST et al, 2000; RIBEIRO et al, 2012). Most of the authors agree that these low pregnancy rates are likely due to numerous factors including changes in physiology, nutritional management of transition period and selection of traits that might potentially have an adverse effect on fertility (LUCY, 2001; SHOOK, 2006; DOBSON et al, 2007; WALSH et al, 2011). In addition, pregnancy rate failures in lactating dairy cattle can be attributed to the absence of a viable embryo due to oocyte quality and 
fertilization issues or inability of the uterus to support blastocyst growth and conceptus elongation (HANSEN, 2007). As a result of the decreasing pregnancy rates, the dairy industry has made progress in developing estrus resynchronization programs before and after pregnancy diagnosis.

An interesting aspect of our study is that the CL was diagnosed in a high proportion of the non-pregnant cows from both groups. It is possible that during the ultrasound examination on day 25 after $\mathrm{AI}$, we detected only the pregnant cows that did not suffer embryonic losses. In the study of Scully et al, (2014), no differences were observed between pregnant and non-pregnant cows from day 18 to day 21 for CL echotexture measurements. With a fertilization rate of $90 \%$, embryonic mortality between pregnancy and day 24 is of approximately 40\%; approximately 70 to $80 \%$ of this loss occurs between day 8 and day 16 (DISKIN et al, 2011). Ricci et al, (2017) concluded that at least half of the non-pregnant cows that maintained their CL until day 32 after AI were initially pregnant but underwent early pregnancy loss. Our study did not evaluate the embryonic losses because there are several risk factors are associated with this, including environmental stress, disease, nutrition, luteal insufficiency, and ovulation of persistent follicles (SILKE et al, 2002; CHEBEL et al, 2004; SANTOS et al, 2004). Thus, it is very difficult to make an association between early pregnancy diagnosis and embryonic loss. Unfortunately, there is little evidence of when the embryonic loss occurs and it is difficult to establish the connection with the mechanism that triggers it (NORTHROP et al, 2019).

The most common measure when cows are found open at pregnancy diagnosis is to apply the treatment with prostaglandin which results in luteolysis followed by a new estrus, typically about 3-4 days later (HEUWIESER et al, 1997). Some authors recommended initiating the Ovsynch protocol for estrus resynchronization even before pregnancy diagnosis (FRICKE et al, 2003). In our study, we used the treatment with prostaglandin only for the non-pregnant cows that presented a CL, while for the rest of the cows we used the Ovsynch program. This reproductive management program consisting in initiation of an estrus synchronization protocol for non-pregnant cows on the day of pregnancy diagnosis (day 25 after AI) generated a pregnancy rate of $33.3 \%(6 / 18)$, which is similar to the results obtained by various studies. Pereira et al, (2013) obtained a pregnancy rate of $26.4 \%$ and $20.1 \%$ when resynchronization protocol was initiated $31 \pm 3$ days after AI for non-pregnant cows that were subjected to pregnancy diagnosis by ultrasonography and transrectal palpation respectively. Moreira et al, (2000) observed similar findings when using an estrus resynchronization protocol starting 20 days after AI, with a reported pregnancy rate of $20 \%$ on day 45 of gestation. Fricke et al, (2003), when evaluating pregnancy per AI using a resynchronization protocol, observed pregnancy rate of 23,34 , and $38 \%$ for cows enrolled in the resynchronization protocol at 19, 26, and 33 days after AI, respectively.

At the same time, there is controversy regarding the use of tools for early pregnancy diagnosis in combination with estrus resynchronization programs. Injecting pregnant cows with GnRH 19 days after the first AI does not improve the calving rate in comparison with the rate obtained with the initiation of the Resynch program 26 or 33 days after the first AI (FRICKE et al, 2003). Similar results were obtained when Resynch program starting on day 21 after timed AI (TAI) was used, with the purpose of initiating a TAI protocol before pregnancy diagnosis (CHEBEL et al, 2003). Moreira et al, (2000) discontinued the aggressive resynchronization program for non-pregnant cows because of the interaction of cows resynchronized with GnRH on day 20 after the TAI in which the embryonic loss from day 20 to 27 after the TAI was increased for bovine somatotropin-treated pregnant cows receiving GnRH but not for untreated pregnant cows. In our opinion, the estrus synchronization program must be initiated in the day of early pregnancy diagnosis (day 25 after AI service) according to the morph-physiological structures identified on the ovaries, because this strategy can improve the pregnancy rate $(56.7 \%$ vs. $37.5 \%)$ while preventing the excessive hormonal use in the dairy industry.

In this study, the small benefit in favor of the synchronization AI protocol for the cows failing to conceive is likely due to the added cost of given hormones. We evaluated this small benefit in favor of E group as a positive net present value for the farm and its association with additional reproductive management decisions should be considered. This profit is not under the influence of the Heifer replacement value, which is low in the studied farm $(\$ 530 /$ heifer). When the value was set at the international standard value $(\$ 1300 /$ heifer) the NPV increased at a value of $\$ 11.5 / \mathrm{cow} /$ year. In another study, Pereira et al., (2013) started the resynchronization at $31 \pm 3$ days after AI and obtained a NPV of $\$ 3.65 /$ cow when pregnancy diagnosis was performed on the same day by ultrasonography compared with pregnancy diagnosis performed $38 \pm 3$ days after AI by transrectal palpation. However, most of the studies applying management practices aiming to reduce the interbreeding interval in cows have been reported to trigger economic advantages, especially for reproductive programs with lower pregnancy rates (TENHAGEN et al, 2004; GIORDANO et al, 2011; GALVÃO et al, 2013). Because there are differences in the reproductive performance among herds (NEVES et al, 2012), management decisions should be based on an economic analysis using observed reproductive outcomes specific for that individual farm (FRICKE et al, 2016). Thus, a variety of strategies consisting in rebreeding 
the non-pregnant cattle can be used in the cattle industry to improve the net present values,

\section{Conclusions}

In this study, we use transrectal ultrasonography for pregnancy diagnosis as an accurate method to identify non-pregnant cows eligible for estrus synchronization program. By rebreeding the non-pregnant cows at earliest opportunity, an improvement of the pregnancy rate and of the net present value can be achieved. The early pregnancy diagnosis combined with simple targeted hormonal interventions, according to the morphological structures identified on the ovaries represents an efficient reproductive management of dairy cattle. This can reduce the excessive use of hormonal therapy in fertility management programs and contribute to the increase of the pregnancy rate and the profitability of dairy farms.

\section{Acknowledgements}

The authors would like to thanks Simona Vlad-Sabie and Iulian Ibănescu for constructive criticism of the manuscript and for English revision. In addition, we would like to thank SCDCB Dancu, Iasi, for providing the data recorded during the study period. The research reported in this publication was supported by the Romanian Ministry of Agriculture and Rural Development by the research grant ADER 8.3.4/2019.

\section{Conflicts of Interest}

The authors declare no conflicts of interest.

\section{References}

1. BROADDUS BMS, DE VRIES A. A comparison of methods for early pregnancy diagnosis. Proceedings 2nd Florida Dairy Road Show 2005.

2. BRAGANÇA GM, MONTEIRO BM, DOS SANTOS ALBUQUERQUE R, DE SOUZA DC et al. Using pregnancy-associated glycoproteins to provide early pregnancy diagnosis in Nelore cows. Livest Sci. 2018; 214: 278-281.

3. COWIE T.A. Pregnancy diagnosis tests: a review. Commonwealth Agricultural bureaux Joint Publication. No. 13, Oxford, UK. 1948: pp. 283.

4. COMMUN L, VELEK K, BARBRY JB, PUN S et al. Detection of pregnancy-associated glycoproteins in milk and blood as a test for early pregnancy in dairy cows. J Vet Diagn Invest. 2016; 28 (3): 207-213.

5. CERRI RL, SANTOS JE, JUCHEM SO, GALVÃO $\mathrm{KN}$ et al. Timed artificial insemination with estradiol cypionate or insemination at estrus in high-producing dairy cows. J Dairy Sci. 2004; 87: 3704-3715.

6. CHEBEL RC, SANTOS JE, CERRI RL, GALVAO $\mathrm{KN}$ et al. Effect of resynchronization with GnRH on day 21 after artificial insemination on pregnancy rate and pregnancy loss in lactating dairy cows. Theriogenology. 2003; 60: 1389-1399.

7. CHEBEL RC, SANTOS JE, REYNOLDS JP, CERRI RL et al. Factors affecting pregnancy rate after artificial insemination and pregnancy loss in lactating dairy cows. Anim Reprod Sci. 2004; 84: 239-255.

8. DE VRIES A. Economic value of pregnancy in dairy cattle. J Dairy Sci. 2006; 89: 3876-3885.

9. DOBSON H, SMITH RF, ROYAL MD, KNIGHT $\mathrm{CH}$ et al. The high-producing dairy cow and its reproductive performance. Reprod Domestic Anim. 2007; 42: 17-23.

10. DISKIN MG, PARR MH, MORRIS DG. Embryo death in cattle: an update. Reprod Fertil Dev. 2011; 24 (1): 244-251.

11. FRICKE PM, GUENTHER JN, WILTBANK MC. Efficacy of decreasing the dose of GnRH used in a protocol for synchronization of ovulation and timed AI in lactating dairy cows. Theriogenology. 1998; 50: 1275-1284.

12. FRICKE PM. Scanning the future - ultrasonography as a reproductive management tool for dairy cattle. J Dairy Sci. 2002; 85: 1918-1926.

13. FRICKE PM, CARAVIELLO DZ, WEIGEL KA, WELLE ML. Fertility of Dairy Cows after Resynchronization of Ovulation at Three Intervals Following First Timed Insemination. J Dairy Sci. 2003; 86: 3941-3950.

14. FRICKE PM, RICCI A, GIORDANO JO, CARVALHO PD. Methods for and implementation of pregnancy diagnosis in dairy cows. Vet Clin $\mathrm{N} \mathrm{Am}$ Food Anim Pract Â. 2016; 32: 165-180.

15. FILTEAU V, DESCOTEAUX L. Predictive values of early pregnancy diagnosis by ultrasonography in dairy cattle. Proc AABP Annu Mtg, Spokane, WA 1998; 31: 170-171.

16. GALVÃO KN, FEDERICO P, DE VRIES A. Schuenemann G.M. Economic comparison of reproductive programs for dairy herds using estrus detection, timed artificial insemination, or a combination. J Dairy Sci. 2013; 96: 2681-2693.

17. GIORDANO JO, FRICKE PM, WILTBANK MC, CABRERA VE. An economic decision-making support system for selection of reproductive management programs on dairy farms. J Dairy Sci. 2011; 94: 62166232.

18. GIORDANO JO, FRICKE PM, CABRERA VE. Economics of resynchronization strategies including chemical tests to identify non-pregnant cows. J Dairy Sci. 2013; 96: 949-961.

19. HANSEN PJ. Exploitation of genetic and physiological determinants of embryonic resistance to elevated temperature to improve embryonic survival in dairy cattle during heat stress. Theriogenology. 2007; 68, (Suppl. 1): S242-S249. 
20. HEUWIESER W, OLTENACU PA, LEDNOR AJ, FOOTE RH. Evaluation of different protocols for prostaglandin synchronization to improve reproductive performance in dairy herds with low estrus detection efficiency. J Dairy Sci. 1997; 80: 2766-2774.

21. HOLTZ W, NIGGEMEYER H. Reliable identification of pregnant dairy cows by double milk progesterone analysis. Livest Sci. 2019; 214: 278-281.

22. JOBST SM, NEBEL RL, MCGILLIARD ML, PELZER KD. Evaluation of reproductive performance in lactating dairy cows with prostaglandin F2 $\alpha$, gonadotropin-releasing hormone, and timed artificial insemination. J Dairy Sci. 2000; 83: 2366-2372.

23. INCHAISRI C, JORRITSMA R, VOS PL, VAN DER WEIJDEN GC et al. Economic consequences of reproductive performance in dairy cattle. Theriogenology. 2010; 74: 835-846.

24. LUCY MC. Reproductive loss in high-producing dairy cattle: where will it end? J Dairy Sci. 2001; 84: 1277-1293.

25. MOREIRA F, RISCO CA, PIRES MF, AMBROSE JD et al. Use of bovine somatotropin in lactating dairy cows receiving timed artificial insemination. J Dairy Sci. 2000; 83: 1237-1247.

26. NEVES RC, LESLIE KE, WALTON JS, LEBLANC SJ. Reproductive performance with an automated activity monitoring system versus a synchronized breeding program. J Dairy Sci. 2012; 95: 5683-5693.

27. NORTHROP EJ, RICH JJJ, RHOADES, JR, PERRY GA. Comparison of two bovine serum pregnancy tests in detection of artificial insemination pregnancies and pregnancy loss in beef cattle. PLoS ONE. 2019; 14(1): e0211179.

28. NORMAN HD, WALTON LM, DÜRR JW. Reproductive status of cows in dairy herd improvement programs and bred using artificial insemination. 2016. https://queries.uscdcb.com/publish/ dhi/current/reproall.html

29. PEREIRA RV, CAIXETA LS, GIORDANO JO, GUARD CL et al. Reproductive performance of dairy cows resynchronized after pregnancy diagnosis at 31 ( \pm 3 days) after artificial insemination (AI) compared with resynchronization at $31( \pm 3$ days $)$ after AI with pregnancy diagnosis at 38 ( \pm 3 days) after AI. J Dairy Sci. 2013; 96: 7630-7639.

30. PIETERSE MC, SZENCI O., WILLEMSE AH, BAJCSY CSA et al. Early pregnancy diagnosis in cattle by means of linear-array Real-time ultrasound scanning of the uterus and a qualitative and quantitative milk progesterone test. Theriogenology. 1990; 33: 697-707.

31. PURSLEY JR, WILTBANK MC, STEVENSON JS, OTTOBRE JS et al. Pregnancy rates in cows and heifers inseminated at a synchronized ovulation or synchronized estrus. J Dairy Sci. 1997a; 80: 295-300.

32. PURSLEY JR, KOSOROK MR, WILTBANK MC. Reproductive management of lactating dairy cows using synchronization of ovulation. J Dairy Sci. 1997b; 80: 301-306.
33. ROSENBAUM A, WARNICK LD. Pregnancy diagnosis in dairy cows by palpation or ultrasound: a survey of US Veterinarians. Proceedings 37th AABP Annual Meeting, Forth Worth, TX Proceedings 2004: pp. 198.

34. REAL LMM, VALENCIA GL, CORRAL A, RENTENIA T. Evaluation of ultrasound for pregnancy diagnosis between 20-40 days post insemination in dairy cows. J Ani Vet Adv. 2006; 5: 949-951.

35. ROMANO JE, THOMPSON JA, FORREST DW, WESTHUSIN ME, TOMASZWESKI et al. Early pregnancy diagnosis by transrectal ultrasonography in dairy cattle. Theriogenology. 2006; 66: 1034-1041.

36. RIBEIRO ES, GALVAO KN, THATCHER WW, SANTOS JEP. Economic aspects of applying reproductive technologies to dairy herds. Anim Reprod. 2012; 9: 370-387.

37. RICCI A, CARVALHO PD, AMUNDSON MC, FRICKE PM. Characterization of luteal dynamics in lactating Holstein cows for 32 days after synchronization of ovulation and timed artificial insemination. J Dairy Sci. 2017; 100: 9851-9860.

38. SANTOS JE, THATCHER WW, CHEBEL RC, CERRI RL et al. The effect of embryonic death rates in cattle on the efficacy of estrus synchronization programs. Anim Reprod Sci. 2004; 82-83: 513-535.

39. SHAHIN M., FRIEDRICH M., GAULY M., HOLTZ W. Pregnancy-associated glycoprotein (PAG) profile of Holstein-Friesian cows as compared to dual-purpose and beef cows. Reprod Domestic Anim. 2014; 49: 618-620.

40. SHOOK GE. Major advances in determining appropriate selection goals. J Dairy Sci. 2006; 89: 13491361.

41. SCULLY S, BUTLER ST, KELLY AK, EVANS ACO, et al. Early pregnancy diagnosis on days 18 to 21 postinsemination using high-resolution imaging in lactating dairy cows. J Dairy Sci. 2014; 97: 3542-3557.

42. SILKE V, DISKIN MG, KENNY DA, BOLAND MP, et al. Extent, pattern and factors associated with late embryonic loss in dairy cows. Anim Reprod Sci. 2002; 71: 1-12.

43. SENGER PL. The estrus detection problem: new concepts, technologies, and possibilities. J Dairy Sci. 1994; 77: 2745-2753.

44. TENHAGEN BA, DRILLICH M, SURHOLT R, HEUWIESER W. Comparison of timed AI after synchronized ovulation to AI at estrus: Reproductive and economic considerations. J Dairy Sci. 2004; 87: 85-94.

45. WALSH SW, WILLIAMS EJ, EVANS AC. A review of the causes of poor fertility in high milk producing dairy cows. Anim Reprod Sci. 2011; 23(3-4): 127-138.

46. WISNICKY W, CASSIDA LE. A manual method for diagnosis of pregnancy in cattle. J Am Vet Med Assoc. 1948; 113: 451. 